DANTAS, M.I.S.; MINIM, V.P.R.; PUSCHMANN, R.; CARNEIRO, J.D.S.; BARBOSA, R.L. Mapa de preferência de couve minimamente processada. Horticultura Brasileira, Brasília, v. 22, n. 1, p. 101-103, jan-mar 2004.

\title{
Mapa de preferência de couve minimamente processada
}

\author{
Maria Inês S. Dantas; Valéria P.R. Minim; Rolf Puschmann; João D.S. Carneiro; Rogério L. Barbosa \\ Universidade Federal de Viçosa, 36570-000 Viçosa-MG; E-mail: msdantas@ufv.br
}

\section{RESUMO}

Determinou-se por meio da técnica de mapa de preferência, a aceitabilidade de diferentes cortes de couve minimamente processada. A separação espacial das amostras de couve sugeriu a existência de três grupos, de acordo com a aceitação das mesmas. As amostras de couve minimamente processada que obtiveram aceitação por um maior número de consumidores foram as de 1 e $2 \mathrm{~mm}$ de largura.

Palavras-chave: Brassica oleraceae cv. acephala, processamento mínimo, aceitação sensorial.

\begin{abstract}
Preference mapping of fresh-cut collard

The acceptability of fresh-cut collard leaves chopped in different widths was determined by employing the preference mapping technique. Spatial separation of samples suggested the existence of three groups, according to their acceptability. Fresh-cut samples showing acceptability by a large number of consumers where 1 and $2 \mathrm{~mm}$ wide.
\end{abstract}

Keywords: Brassica oleraceae cv. acephala, fresh-cut collard, sensorial acceptance.

\section{(Recebido para publicação em 24 de março de 2002 e aceito em 22 de setembro de 2003)}

$\mathrm{O}$ produtos minimamente processa dos, conhecidos como fresh cut, têm-se destacado no mercado, pois seguem a tendência mundial de consumo de alimentos saudáveis, frescos e de alta qualidade. O propósito do seu fornecimento é o de disponibilizar um produto pronto para usar, que não requeira nenhuma preparação posterior significativa por parte do consumidor, em termos de seleção, limpeza, lavagem ou cortes. Outra grande vantagem desses itens é a redução praticamente total dos desperdícios (Junqueira e Luengo, 2000). Adiminuição do tempo disponível para o preparo das refeições, o aumento do poder de compra e a conscientização do consumidor em relação à saúde, são fatores que, combinados, contribuem para aumentar de forma significativa a demanda desses alimentos (Baldwin et al., 1995). O termo minimamente processado tornou-se comum na indústria de alimentos e entre os consumidores nos anos 90 (Mertens e Knorr, 1992) e, de acordo com a International Fresh Cut Produce Association (1999), pode ser definido como qualquer alteração física em frutas e hortaliças, mas que mantém o estado fresco do produto.

A determinação da aceitação pelo consumidor é parte crucial no processo de desenvolvimento ou melhoramento de produtos. Os testes de aceitação ou afetivos requerem equipe com grande número de participantes que represen- tem a população de consumidores atuais ou potenciais do produto. Entre os métodos mais empregados para medida da aceitação de produtos está a Escala Hedônica, onde o consumidor expressa sua aceitação pelo produto, seguindo uma escala previamente estabelecida que varia gradativamente com base nos termos gosta e desgosta. (Chaves e Sproesser, 1993).

Os resultados de testes afetivos (testes com consumidores) vêm, tradicionalmente, sendo avaliados por análise de variância univariada (ANOVA) e testes de comparação de médias, comparando-se a aceitação média entre produtos.

Segundo Polignano et al. (1999) esta análise global, considerando conjuntamente as avaliações de todos os consumidores, implica em assumir que todos apresentam o mesmo comportamento, desconsiderando suas individualidades. Cita ainda que os dados podem não estar sendo bem visualizados, a ponto de se perder informações interessantes sobre diferentes segmentos de mercado. A técnica de Mapa de Preferência pode solucionar este problema e também permitir a associação da impressão que os consumidores têm de um produto com suas características sensoriais.

Com a finalidade de analisar os dados afetivos, levando-se em consideração a resposta individual de cada consumidor, e não somente a média do gru- po de consumidores que avaliaram os produtos, foi desenvolvida a técnica intitulada Mapa de Preferência que tem sido largamente utilizada por cientistas da área de análise sensorial (Behrens et. al., 1999).

Tendo em vista estas considerações, este estudo objetivou avaliar a aceitação de diferentes cortes de couve minimamente processada, aplicando a técnica Mapa de Preferência.

\section{MATERIAL E MÉTODOS}

Folhas de couve (Brassica oleraceae var. acephala) foram colhidas na horta da Universidade Federal de Viçosa, no estágio de desenvolvimento correspondente à colheita comercial, e pré-resfriadas antes de serem submetidas ao processamento.

As folhas foram selecionadas, lavadas em água corrente, tiveram seus pecíolos retirados e posteriormente foram submetidas à sanitização. $\mathrm{O}$ processo de sanitização consistiu na imersão das folhas em água resfriada a $5^{\circ} \mathrm{C}$, contendo $150 \mathrm{ppm}$ de cloro ativo, por 10 minutos (Simons e Sanguansri, 1997).

$\mathrm{Na}$ etapa seguinte, as folhas foram fatiadas em processador de alimentos industrial equipado com lâminas para diferentes larguras $(1 ; 2 ; 5$ e $10 \mathrm{~mm}) \mathrm{e}$, em seguida, submetidas ao enxágüe em água resfriada a $5^{\circ} \mathrm{C}$ contendo $3 \mathrm{ppm}$ de cloro ativo. 
Quadro 1. Ficha de avaliação utilizada para o teste de aceitação. Viçosa, UFV, 2001.

Nome: $\frac{\text { Data: }}{\text { Por favor, avalie a amostra utilizando a escala para descrever o quanto você gostou ou }}$
desgostou do produto, em relaçäo a APARÉNCIA. Marque a posiçäo da escala que melhor reflita
seu julgamento.
Código da amostra:
( ) Gostei extremamente
( ) Gostei muito
( ) Gostei moderadamente
( ) Gostei ligeiramente
( ) Indiferente
( ) Desgostei ligeiramente
( ) Desgostei moderadamente
( ) Desgostei muito
( ) Desgostei extremamente
Comentários:

Tabela 1. Freqüências das notas atribuídas, em cada um dos termos hedônicos, às quatro amostras de couve minimamente processadas. Viçosa, UFV, 2001.

\begin{tabular}{lccccc}
\hline \multirow{2}{*}{ Termos hedõnicos } & \multirow{2}{*}{ Notas } & \multicolumn{4}{c}{ Largura de couve minimamente processada (mm) } \\
\cline { 3 - 6 } & & $\mathbf{1}$ & $\mathbf{2}$ & $\mathbf{5}$ & $\mathbf{1 0}$ \\
\hline Gostei extremamente & 9 & 43 & 31 & 2 & 3 \\
Gostei muito & 8 & 32 & 48 & 14 & 11 \\
Gostei moderadamente & 7 & 12 & 13 & 10 & 6 \\
Gostei ligeiramente & 6 & 4 & 2 & 15 & 6 \\
Indiferente & 5 & 3 & 2 & 6 & 7 \\
Desgostei ligeiramente & 4 & 0 & 0 & 13 & 8 \\
Desgostei moderadamente & 3 & 1 & 0 & 13 & 10 \\
Desgostei muito & 2 & 3 & 2 & 15 & 23 \\
Desgostei extremamente & 1 & 2 & 2 & 12 & 26 \\
\hline
\end{tabular}

A couve minimamente processada foi centrifugada por 10 minutos, utilizando-se uma centrífuga doméstica, com velocidade constante equivalente a $800 \mathrm{~g}$, com o objetivo de retirar o excesso de água e os exsudados celulares provenientes das etapas de corte, sanitização e enxágüe. Acondicionaramse $150 \mathrm{~g}$ de couve minimamente processada, em embalagens de poliolefina multicamadas.

A aceitabilidade sensorial da aparência das quatro amostras de couve, com 1,2; 5 e $10 \mathrm{~mm}$, foi avaliada por 100 consumidores, em dois estabelecimentos comerciais da cidade de Viçosa, utilizando uma Escala Hedônica de nove pontos para as avaliações, sendo os extremos de valor 1 atribuído ao termo hedônico "desgostei extremamente" e de valor 9 atribuído ao termo "gostei extremamente" (Figura 1).

Para obtenção do Mapa de Preferência Interno ou Análise de Preferência Multidimensional (MDPREF), os dados de aceitação (teste de consumidor) foram organizados numa matriz de amostras (em linhas) e consumidores (em colunas), e esta submetida à Análise de Componentes Principais (ACP) (Carneiro, 2001).

Os resultados foram expressos em um gráfico de dispersão das amostras (tratamentos) em relação aos dois primeiros componentes principais e em outro representando os "loadings" (cargas) da ACP (correlações dos dados de cada consumidor com os dois primeiros componentes principais).

\section{RESULTADOS E DISCUSSÃO}

Os resultados da avaliação da aceitabilidade sensorial das quatro amostras de couve minimamente processada estão apresentados na Tabela 1 . As amostras com 1 e 2 mm foram classificadas por 91 e 94 consumidores, respectivamente, entre os termos hedônicos "gostei extremamente" e "gostei ligeiramente", indicando assim que foram bem aceitas pela maioria dos consumidores. A distribuição das notas atribuídas para a amostra com $5 \mathrm{~mm}$ de largura foi a mais homogênea entre os 9 termos hedônicos, mas 53 consumidores fizeram a classificação entre os termos hedônicos "desgostei ligeiramente" e "desgostei 
extremamente" indicando que rejeitaram o produto. A amostra com $10 \mathrm{~mm}$ foi rejeitada por 67 consumidores.

Com os dados obtidos no teste de aceitação das quatro amostras de couve minimamente processadas foi realizada a análise do Mapa de Preferência Interno (Figuras 1 e 2). O primeiro componente principal (PC) explicou $89 \%$ e o segundo $8 \%$, totalizando, portanto, $97 \%$ da variância entre as amostras quanto à sua aceitação.

A separação espacial das amostras de couve minimamente processada sugere a existência de três grupos de acordo com a aceitação das mesmas, sendo um grupo formado pelas amostras de couve de 1 e $2 \mathrm{~mm}$ de largura e os outros pelas amostras de $5 \mathrm{~mm}$ e de $10 \mathrm{~mm}$ (Figura 1).

$\mathrm{Na}$ Figura 2, cada ponto representa as correlações entre os dados de aceitação de um consumidor e os dois primeiros componentes principais. Os consumidores mais próximos do centro do gráfico não estão correlacionados com nenhum dos dois componentes principais e contribuem pouco para a discriminação das amostras, ou seja, são consumidores que consideram as amostras com aceitação semelhante. Este grupo é formado por um número pequeno de consumidores. Por outro lado, consumidores correlacionados com pelo menos um dos componentes, consideram diferença na aceitação das amostras. Para a grande maioria dos consumidores houve correlação positiva com o primeiro componente principal, indicando que atribuíram notas mais elevadas para as amostras de couve minimamente processadas com 1 e 2 mm de largura (amostras mais à direita no gráfico, Figura 1$)$.

\section{LITERATURA CITADA}

BALDWIN, E.A.; NISPEROS-CARRIEDO, M.O.; BAKER, R.A. Edible coatings for lightly processed fruits and vegetables. HortScience, v.30, n.1, p.35-38, 1995

BEHRENS, J.H.; SILVA, M.A.A.P.; WAKELING, I.N. Avaliação da aceitação de vinhos brancos varietais brasileiros através de testes sensoriais afetivos e técnica multivariada de mapa de preferência interno. Ciência e Tecnologia de Alimentos, Campinas, v.19. n.2, mai./ago. 1999.

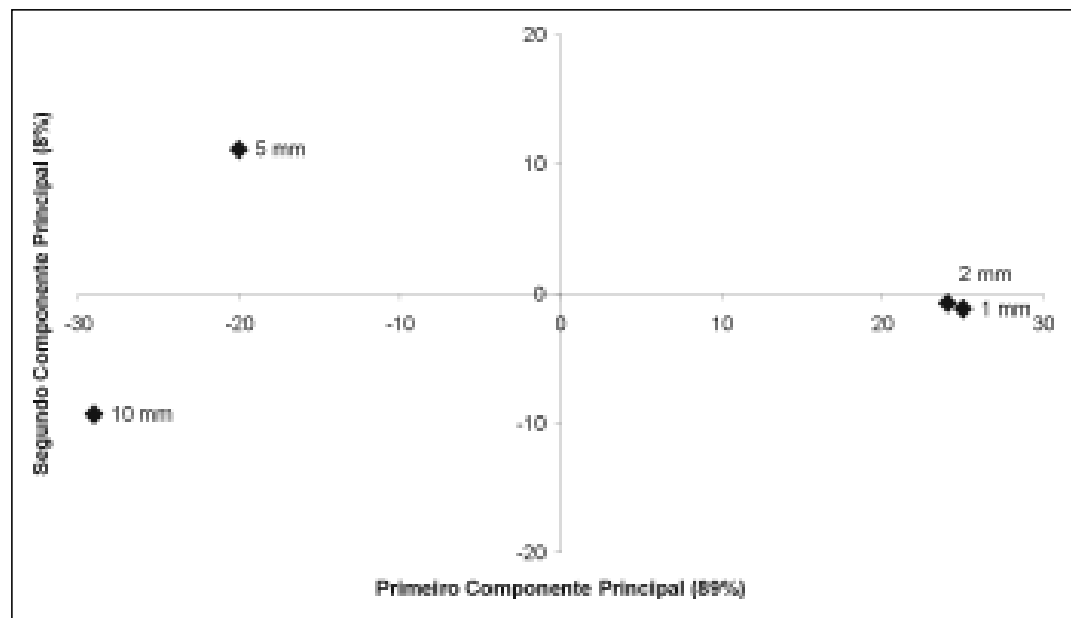

Figura 1. Dispersão das amostras de couve minimamente processada em relação à aceitação pelos consumidores. Viçosa, UFV, 2001.

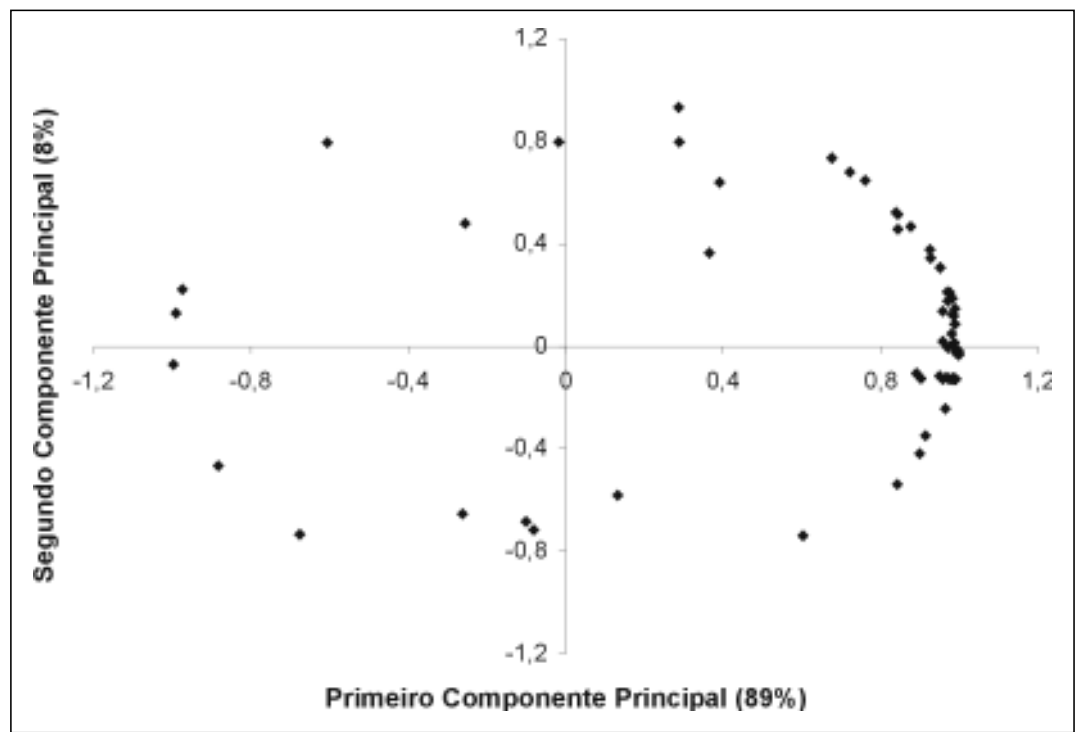

Figura 2. "Loadings" (Cargas) - Correlações entre os dados de aceitação de cada consumidor e os dois primeiros componentes principais. Viçosa, UFV, 2001.

CARNEIRO, J.C.S. Processamento Industrial de Feijão, Avaliação Sensorial Descritiva e Mapa de Preferência. 2001.90 f. (Tese mestrado), UFV, Viçosa.

CHAVES, J.B.P.; SPROESSER, R.L. Práticas de laboratório de análise sensorial de alimentos e bebidas. Viçosa: Universidade Federal de Viçosa, 1993, $81 \mathrm{p}$.

INTERNATIONAL FRESH CUT PRODUCE ASSOCIATION. Fresh-cut produce handling guidelines. 3. ed. Produce Marketing, 1999. $39 \mathrm{p}$ JUNQUEIRA, A.H.; LUENGO, R.F.A. Mercado diferenciados de hortaliças. Horticultura Brasileira, Brasília, v.18, n.2, 2000.
MERTENS, B.; KNORR, D. Developments of nonthermal processes for food preservation. Food Technology, v.43, n.5, p.124-133, 1992.

POLIGNANO, L.A.C.; DRUMOND, F.B.; CHENG, L.C. Mapa de preferência: Uma ponte entre marketing e P\&D. In: CONGRESSO BRASILEIRO DE GESTÃO DO DESENVOLVIMENTO DE PRODUTO, 2, 2000, São Carlos. Anais... 2000. p.96-102.

SIMONS, L.K.; SANGUANSRI, P. Advances in the washing of minimally processed vegetables. Food Australia, v.49, n.2, p.75-80, 1997. 